Braz J Med Biol Res, October 2011, Volume 44(10) $992-999$

doi: 10.1590/S0100-879X2011007500113

\section{A link between sleep loss, glucose metabolism and adipokines}

H.G. Padilha, C.A. Crispim, I.Z. Zimberg, D.A. De-Souza, J. Waterhouse, S. Tufik and M.T. de-Mello

The Brazilian Journal of Medical and Biological Research is partially financed by

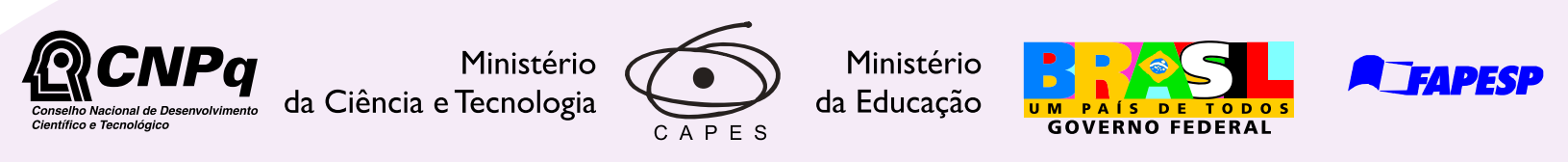

Institutional Sponsors
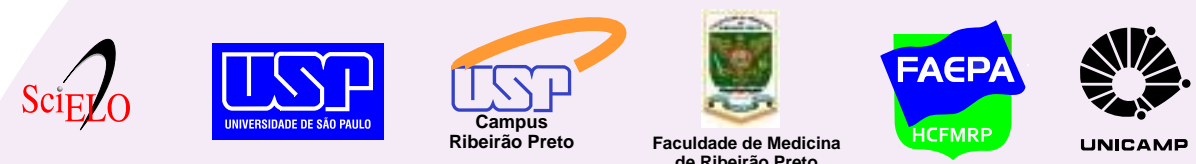

UNICAMP

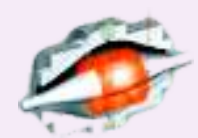

$\oplus$ SHIMADZU

Explore High - Performance MS Orbitrap Technology In Proteomics \& Metabolomics

$\underset{\text { analitica }}{\text { analiticaweb.com.br }}$ SCIENTIFIC 


\title{
A link between sleep loss, glucose metabolism and adipokines
}

\author{
H.G. Padilha ${ }^{1}$, C.A. Crispim ${ }^{1,2}$, I.Z. Zimberg ${ }^{1}$, D.A. De-Souza ${ }^{2}$, \\ J. Waterhouse ${ }^{3}$, S. Tufik ${ }^{1}$ and M.T de-Mello ${ }^{1}$ \\ 1Departamento de Psicobiologia, Universidade Federal de São Paulo, São Paulo, SP, Brasil \\ ${ }^{2}$ Faculdade de Medicina, Universidade Federal de Uberlândia, Uberlândia, MG, Brasil \\ ${ }^{3}$ Research Institute for Sport and Exercise Sciences, Liverpool John Moores University, Liverpool, UK
}

\begin{abstract}
The present review evaluates the role of sleep and its alteration in triggering problems of glucose metabolism and the possible involvement of adipokines in this process. A reduction in the amount of time spent sleeping has become an endemic condition in modern society, and a search of the current literature has found important associations between sleep loss and alterations of nutritional and metabolic contexts. Studies suggest that sleep loss is associated with problems in glucose metabolism and a higher risk for the development of insulin resistance and type 2 diabetes mellitus. The mechanism involved may be associated with the decreased efficacy of regulation of the hypothalamus-pituitary-adrenal axis by negative feedback mechanisms in sleepdeprivation conditions. In addition, changes in the circadian pattern of growth hormone $(\mathrm{GH})$ secretion might also contribute to the alterations in glucose regulation observed during sleep loss. On the other hand, sleep deprivation stress affects adipokines - increasing tumor necrosis factor- $\alpha$ (TNF- $\alpha$ ) and interleukin-6 (IL-6) and decreasing leptin and adiponectin -, thus establishing a possible association between sleep-debt, adipokines and glucose metabolism. Thus, a modified release of adipokines resulting from sleep deprivation could lead to a chronic sub-inflammatory state that could play a central role in the development of insulin resistance and type 2 diabetes mellitus. Further studies are necessary to investigate the role of sleep loss in adipokine release and its relationship with glucose metabolism.
\end{abstract}

Key words: Glucose metabolism; Insulin resistance; Sleep loss; Adipokines; Type 2 diabetes mellitus; Inflammatory status

\section{Introduction}

Sleep loss due to voluntary bedtime restriction has become common in recent years, produced by the demands and opportunities of modern society (1). Sleep-deprivation can be total, when no sleep is allowed, or partial, when the retiring time is delayed or the rising time is advanced. In the United States, the proportion of young adults with a period of sleep shorter than $7 \mathrm{~h}$ a day has increased from $15.6 \%$ in 1960 to $37.1 \%$ in 2001-2002 (2). In Brazil, sleep habits of the adult population in the city of São Paulo, estimated in surveys carried out in 1987 and 1995, have shown a slight, but significant, change behavior during this time. Total hours slept varied from 7:45 to 9:00 h in 1987 to 7:40 to $8: 40 \mathrm{~h}$ in 1995 . There was also a significant decrease in total hours slept during the weekends in 1995 compared to 1987 (3).

Recent studies have described a significant impairment of glucose control in individuals who have decreased sleep duration $(1,4,5)$; in addition, these subjects are more susceptible to metabolic problems such as insulin resistance $(1,5)$ and type 2 diabetes mellitus (DM2) (6-9).

The mechanism involved in impaired glucose metabolism following changes in the sleep-wake rhythm seems to be a decreased efficacy of the negative-feedback regulation of the hypothalamus-pituitary-adrenal (HPA) axis (1). Recent studies have indicated that adipokines may be implicated in these alterations $(10,11)$. This article discusses the influence of sleep and sleep loss on the development of insulin resistance and DM2, and the mechanisms involved in this process.

\section{Review protocol}

A computer-based search of the literature indexed in MEDLINE was made using the key words: glucose

Correspondence: M.T de-Mello, CEPE, UNIFESP, Rua Marselhesa, 500, 9o andar, 04020-060 São Paulo, SP, Brasil.

Fax: +55-11 5572-0177. E-mail: tmello@psicobio.epm.br

Received March 3, 2011. Accepted August 17, 2011. Available online September 2, 2011. Published October 10, 2011. 
metabolism, insulin resistance, adipokines, adiponectin, interleukin-6 (IL-6), leptin, tumor necrosis factor-alpha (TNF- $\alpha$ ), sleep deprivation, and sleep loss. Studies that have measured the relationship between sleep duration and glucose metabolism are discussed in the first part of the article; in the second, the relationships between the adipokines/sleep loss and changes in glucose metabolism are considered. Studies that evaluated alterations in adipokines and in glucose metabolism as a consequence of sleep apnea have been excluded.

\section{Type 2 diabetes mellitus and sleep duration}

Several studies have examined the association between sleep duration, sleep disturbance, and the development of DM2. Analysis of cross-sectional data from the Sleep Heart Health Study revealed that reduced sleep duration was associated with an increased prevalence of insulin resistance and DM2, after controlling for sleep-disordered breathing, a condition that may independently influence glucose control (12). Trenell et al. (9) found a U-shaped relationship between sleep duration and the incidence of DM2, as did Ayas et al. (6), Chaput et al. (13), and Yaggi et al. (14). In this last prospective-cohort study (14), middle-aged and elderly men reporting short sleep duration ( $\leq 5: 00$ or $6: 00 \mathrm{~h}$ of sleep per night) were twice as likely to develop DM2 as those reporting >8:00 h of sleep per night. Similarly, those who reported long sleep duration $(>8: 00$ $\mathrm{h}$ of sleep per night) were more than three times as likely to develop DM2 over the follow-up period, confirming the $U$-shaped relationship between sleep duration and DM2. The elevated risk remained essentially unchanged after adjustment for age, hypertension, smoking status, selfrated health status, education, and waist circumference $(\mathrm{RR}=1.95[95 \% \mathrm{Cl}=0.95-4.01]$ for $\leq 5$ or $6 \mathrm{~h}$ and $\mathrm{RR}=$ $3.12[95 \% \mathrm{Cl}=1.53-6.37]$ for $>8 \mathrm{~h}$ ).

Cappuccio el al. (15) conducted a meta-analysis to assess the relationship between habitual sleep disturbances and the incidence of DM2 and to obtain an estimate of the risk. Ten studies (13 independent cohort samples; 107,756 male and female participants, follow-up range 4.2-32 years, and 3586 incident cases of DM2) were included. In the analysis stratified by gender, no differences were detected between short duration of sleep or difficulty in maintaining sleep and the development of DM2.

There is insufficient evidence regarding the effect of gender on the relationship between sleep duration and DM2 $(16,17)$. Most of the evidence that does exist has come from samples composed of both genders or of females only. A prospective study conducted by Mallon et al. (8) followed a random sample of 1170 subjects aged $45-65$ years and initially free of DM2, for 12 years. Men $(N=550)$ who had developed DM2 at follow-up more often reported short sleep duration ( $\leq 5 \mathrm{~h}$ per night) $(16.0$ vs $5.9 \%, \mathrm{P}<0.01)$, difficulties initiating sleep (16.0 vs $3.1 \%, P<0.001)$, and difficulties maintaining sleep $(28.0$ vs $6.3 \%, \mathrm{P}<0.001)$ than did those who did not develop DM2. However, short or long sleep durations or sleep complaints did not influence the risk of new cases of DM2 among women $(N=620)$.

Tuomilehto et al. (18) examined the association between sleep duration and DM2 and abnormal glucose tolerance among 1336 men and 1434 women, aged 4574 , who participated in a survey over a 2-year period. In contrast to the study cited previously, these investigators found that short $(6 \mathrm{~h})$ or long ( $8 \mathrm{~h}$ ) sleep duration was related to an increased risk of DM2 in middle-aged women, but not in men. Also, Ayas et al. (6), who studied a cohort of 70,026 women enrolled in the Nurses Health Study, found an increased risk of incidence of symptomatic DM2 over 10 years among those reporting sleep durations of 5 $\mathrm{h}$ or less compared to those who slept 7-8 h. These results were obtained after numerous covariates were controlled (hypercholesterolemia, hypertension, smoking, snoring, exercise, alcohol, depression, postmenopausal hormone use, and family history of DM2) (18).

The failure to detect any association between sleep duration and diabetes in men may be due to the fact that men are known to have a higher overall incidence of sleep-disordered breathing with obstructive sleep apnea than women, and this may be one major reason for their disturbed sleep patterns (18). Testosterone levels can also mediate the effects of both short and long sleep duration on DM2 risk, and could presumably explain the difference between genders in this aspect. Yaggi et al (14), in the same study cited earlier, pointed out that RRs were altered considerably for the two extreme sleep groups ( $\leq 5$ and $>8$ $\mathrm{h}$ of sleep per night) when adjusted for testosterone (1.51 [0.71-3.19] for $\leq 5 \mathrm{~h}$ and 2.81 [1.34-5.90] for $>8 \mathrm{~h}$ ), suggesting that the effects of sleep on diabetes could be mediated via changes in endogenous testosterone levels. Previous studies have shown that low levels of testosterone have been associated with risk factors for diabetes (19) and elevated levels of insulin and glucose $(20,21)$. Low levels of testosterone have been related to diabetes in cohort studies (21). In clinical studies, administration of testosterone to obese men improved insulin sensitivity (22) and, conversely, insulin is also thought to regulate testosterone (23). In addition, previous studies have also linked sleep disruption to reduced testosterone levels (24).

There is some evidence of a U-shape relationship between sleep duration and DM2, demonstrating that extremes of sleep time in either direction may be associated with this important disease. In addition, researches have shown an important association between short sleep duration and the development of DM2 in both genders, although some studies suggest that the relationship is stronger in women. Anyway, we can infer that the differences between genders has not yet been demonstrated conclusively and further studies are needed for this hypothesis to be actually confirmed. 


\section{Insulin resistance, glucose tolerance and sleep loss}

In healthy individuals, plasma glucose homeostasis results from a tightly controlled balance between glucose delivery (from the gut in the post-prandial state and from the liver in the post-absorptive state) and glucose utilization. Insulin plays a key role in this process, by inhibiting hepatic glucose production and by stimulating glucose uptake in insulin-sensitive tissues (mainly skeletal muscle and adipose tissue) (1). Insulin resistance is defined as a state where a normal or elevated insulin level produces an attenuated biological response; classically, such a state refers to impaired sensitivity to insulin-mediated glucose disposal (1). $\beta$-cells can compensate for a small degree of insulin resistance but the hyperglycemic state occurs when $\beta$-cell function is unable to be sufficiently up-regulated, and so DM2 develops (25).

Spiegel et al. (5) analyzed glucose tolerance in 11 young men after time in bed had been restricted to $4 \mathrm{~h}$ per night for 6 nights (sleep-debt condition). The investigators compared this condition with measurements taken at the end of a sleep-recovery period (fully rested condition), when participants had been allowed $12 \mathrm{~h}$ per night in bed for 6 nights. Investigators found that glucose effectiveness, which quantifies the ability of glucose to mediate its own disposal independently of insulin, was 30\% lower in the sleep-debt condition than after the sleep-recovery condition (1.7 vs $2.6 \% / \mathrm{min}, \mathrm{P}<0.0005)$. The investigators pointed out that this difference in glucose effectiveness was nearly identical to that reported between groups of patients with non-insulindependent diabetes and normoglycemic white men (1.4 vs $2.6 \% / \mathrm{min}$ ) (26). In addition, the acute insulin response to glucose was $30 \%$ lower in the sleep-debt condition than in the sleep-recovery condition (304 vs $432 \mathrm{pmol} / \mathrm{min}, \mathrm{P}$ $<0.04)$. This evidence indicates an important impairment of glucose metabolism due to acute total sleep restriction; therefore, the possibility exists that sleep loss may result in long-term adverse effects on glucose tolerance.

In another study, Van Cauter et al. (4) investigated the roles of circadian rhythmicity (intrinsic effects of time of day independent of the sleep or wake condition) and sleep (intrinsic effects of the sleep condition, irrespective of the time of day) on the 24-h variation in glucose tolerance. The study included eight healthy men and the investigators analyzed glucose and insulin secretion rates during $8 \mathrm{~h}$ of nocturnal sleep followed by $28 \mathrm{~h}$ of wakefulness and $8 \mathrm{~h}$ of daytime sleep. To avoid confounding effects of prolonged fasting or meal ingestion, intravenous glucose was infused at a constant rate throughout the study period without waking the subjects. During nocturnal sleep, glucose levels and insulin secretion increased by $31 \pm 5$ and $60 \pm 11 \%$, respectively, and returned to baseline in the morning. During sleep deprivation, glucose levels and insulin secretion rose to a maximum at a time corresponding to the begin- ning of the habitual sleep period. However, the magnitude of this circadian rise was roughly half the amplitude of the rise seen during nocturnal sleep (16.6 $\pm 4.7 \%$ for glucose and $49.3 \pm 7.6 \%$ for insulin secretion). Daytime sleep was associated with a rise above pre-sleep levels of $16.3 \pm 3.4$ and $54.6 \pm 7.1 \%$ in glucose levels and insulin secretion, respectively. The investigators also demonstrated that the profiles of insulin concentrations paralleled those of glucose and insulin secretory rates during nocturnal sleep and during daytime sleep but a nocturnal acrophase in the absence of sleep was detected in only 4 of the 8 subjects. This lack of parallelism between the profiles of insulin secretion and peripheral insulin concentrations during sleep deprivation reflected a circadian variation in insulin clearance, with clearance rates $30-40 \%$ higher during the first half of the habitual sleep period (23:00-3:00; $1.57 \pm 0.20 \mathrm{~L} / \mathrm{min})$ than in the morning (8:00-11:00; $1.16 \pm 0.13 \mathrm{~L} / \mathrm{min}, \mathrm{P}<0.01)$. These findings are consistent with the concept that both circadian rhythmicity and sleep modulate glucose levels, insulin secretion and insulin clearance (4).

Considering the longer-term effects of sleep deprivation, Mander et al. (27) studied 27 non-obese patients who were either chronic short sleepers (sleeping $<6.5$ h on weekdays), or normal sleepers (sleeping 7.5-8.5 h). Sleep diaries were confirmed by wrist actigraphy for 8 consecutive nights. On the last 2 days of the study, patients were submitted to a glucose tolerance test. Both groups had normal basal glucose levels, but short sleepers had significantly higher levels of basal C peptide - a marker of insulin secretion. The insulin sensitivity of these short sleepers was also $40 \%$ lower than normal. This suggests that metabolic responses might change when sleep debt becomes chronic. If this is the case, then it has been argued that the initial impairment of glucose tolerance and of the responsiveness of $\beta$-cells might, if extended, foster the subsequent development of insulin resistance (25).

\section{Roles of counter-regulatory hormones, cortisol and growth hormone, in the changes in glucose metabolism observed during conditions of sleep loss}

Disturbances in the secretory profiles of the counterregulatory hormones, cortisol and growth hormone $(\mathrm{GH})$, may also contribute to the alterations in glucose regulation observed during sleep loss (28).

Cortisol has an immediate effect on the secretion of insulin, inducing inhibition in the absence of changes in glucose concentration (29). After partial and total sleep deprivation, plasma cortisol levels were significantly higher during the night in young men who had been sleep-deprived (37 and $45 \%$ increases, $P=0.03$ and 0.003 , respectively) (30). This metabolic response may reflect a decreased efficacy of the negative-feedback regulation of the HPA axis (31). Simulating a sleep-debt condition, Spiegel et al. (5) analyzed 11 young men whose time in bed had been restricted to 4 h per night for 6 nights. Compared to the sleep-recovery 
condition, sleep debt was associated with alterations in the 24-h profile of plasma cortisol, including a shorter quiescent period (537 vs $634 \mathrm{~min}, \mathrm{P}<0.03$ ), largely due to a delay in its onset of nearly $1.5 \mathrm{~h}$ (at 19:30 [47 min] vs 17:01 h [43], $\mathrm{P}<0.04)$. In addition, the activity of the sympathetic nervous system, measured by heart rate variability, was also increased $(P<0.02)$. It is possible that these changes are linked and reflect the fact that sleep deprivation leads to stress and over-stimulation of the sympathetic system, with a consequent increase in cortisol secretion.

Disorders in the profile of $\mathrm{GH}$ secretion might also contribute to the alterations in glucose regulation observed during sleep loss. $\mathrm{GH}$ is secreted in a series of pulses throughout the 24-h cycle, with greater changes in concentration due to more frequent and larger secretory pulses taking place during sleep (32). In normal adults, peak plasma concentrations of $\mathrm{GH}$ occur during the first half of sleep $(33,34)$. The rapid anti-insulin-like effects of the $\mathrm{GH}$ released during sleep (32) are responsible for reducing glucose uptake by peripheral tissues (1).

Plat et al. (31) showed that sleep restriction was associated with a longer elevation of $\mathrm{GH}$ during the night. Spiegel et al. (28) evaluated the effects of semi-chronic partial sleep loss on the 24-h GH profile in 11 young men. The sleep-loss protocol consisted of 16 consecutive nights in a Clinical Research Center: 3 nights with $8 \mathrm{~h}$ in bed from 23:00 to 7:00 h; 6 nights with time in bed limited to a 4-h period from 1:00 to 5:00 h, and 7 nights with $12 \mathrm{~h}$ in bed from 21:00 to 9:00 h. Unexpectedly, after 1 week of bedtimes reduced to $4 \mathrm{~h}$, all subjects exhibited a $\mathrm{GH}$ pulse before sleep onset and this pre-sleep onset pulse was the largest secretory episode of the 24-h cycle for 5 of the subjects. As a result, the mean 24-h profiles of plasma $\mathrm{GH}$ and $\mathrm{GH}$ secretory rates during the state of sleep debt exhibited a biphasic pattern of nocturnal release, with a large pulse occurring during waking (at around the usual time of sleep onset on a standard 8-h bedtime schedule) followed by a second pulse after the onset of restricted sleep. The biphasic nature of the $\mathrm{GH}$ secretory pattern during sleep restriction resulted in a longer duration of exposure of peripheral tissues to elevated $\mathrm{GH}$ concentrations ( $>4 \mu \mathrm{g} / \mathrm{L}$ ) during sleep extension ( $252 \pm 25$ vs $205 \pm 33 \mathrm{~min}, \mathrm{P}=0.02)$. This secretory pattern contrasts with the mean profiles during sleep extension that present the usual single nocturnal $\mathrm{GH}$ pulse early in sleep. These findings of an extended time of exposure of peripheral tissues to higher $\mathrm{GH}$ levels are potentially important in subjects who are sleep deprived, because such changed levels are related to adverse effects with regard to glucose regulation.

\section{Roles of adipokines and sleep loss in the changes in glucose metabolism}

In recent years, it has been recognized that white adipose tissue is not just an energy-storage organ, but also an active participant in energy homeostasis and physiological functions such as immunity and inflammation (35). Adipose tissue functions as an endocrine organ and secretes a number of bioactive peptides and proteins, collectively termed "adipokines", including leptin, adiponectin and resistin, as well as cytokines, such as TNF- $\alpha$ and IL-6 (36).

Much evidence produced during the past decade has shown that the release of adipokines by either adipocytes or adipose tissue-infiltrated macrophages leads to a chronic sub-inflammatory state that could play a central role in the development of disorders of glucose metabolism (36). Moreover, it has been shown that adipokines such as TNF- $\alpha$, IL-6, and C-reactive protein (CRP) are present at increased concentrations in individuals who are insulin-resistant and obese, and these biomarkers predict the development of DM2 (37). Also, stress due to sleep deprivation affects inflammatory markers, linking sleep-debt, adipokines and insulin resistance (38).

\section{TNF- $\alpha$}

TNF- $\alpha$ is a cytokine that is expressed by macrophage and other cell types and whose expression is up-regulated in adipose tissue and/or skeletal muscle of obese, insulinresistant humans and animals (39). Some evidence from the literature has suggested that TNF- $\alpha$ can be considered to be a molecular link between obesity and insulin resistance (39).

A number of studies have demonstrated that TNF- $\alpha$ alters the insulin-signaling pathway in cultured cells in vivo. Anti-TNF- $\alpha$ antibodies ameliorate insulin sensitivity in obese rodents, and TNF-a-deficient mice are protected from obesity-induced insulin resistance when living on a high-fat diet (38). Currently, however, the molecular mechanism whereby TNF- $\alpha$ attenuates the insulin-signaling pathway is not well understood. Potential mechanisms by which adipose tissue TNF- $\alpha$ could increase insulin resistance include increased release of free fatty acid (FFA) by adipocytes, reduction of adiponectin synthesis, and impairment of insulin signaling (39).

In humans, the soluble receptor for TNF- $\alpha$ is a normal constituent of cerebrospinal fluid and inhibits sleep (11). This receptor also reduces the increase in non-rapid eye movement (nonREM) sleep (mainly stages 3 and 4 ) that normally occurs after sleep deprivation (40). These findings provide very strong evidence supporting the hypothesis that TNF- $\alpha$ plays a key role in sleep homeostasis (41).

In humans, sleep loss also affects the TNF- $\alpha$ system. In a study of mild sleep loss ( $2 \mathrm{~h}$ per night for 7 nights) in healthy men $(N=12)$ and women $(N=13)$, sleep restriction was associated with a significant increase (post-minus presleep restriction) in the overall $24 \mathrm{~h}$ TNF secretion cycle in men $(0.26 \pm 0.1 \mathrm{pg} / \mathrm{mL} ; \mathrm{P}<0.01)$, but not in women $(-0.06$ $\pm 0.03 ; P=N S)(11)$. Thus, in men, the increase in TNF- $\alpha$ following sleep deprivation might lead to impaired glucose metabolism. 


\section{IL-6}

IL-6 is a pro-inflammatory cytokine shown to modify insulin sensitivity (42). Al-Khalili et al. (43) reported that IL-6 directly enhances glucose uptake and metabolism and increases insulin sensitivity in cultured myotubes prepared from human skeletal muscle biopsies. Signaling pathways via AMP-activated protein kinase (AMPK) (44) and phosphatidylinositol 3-kinase (43) have been implicated in the effects of IL-6 on glucose metabolism in cultured cells.

Of the adipokines, IL- 6 has been shown to have the strongest correlation with insulin resistance and associated complications (42). Plasma levels of IL-6 are 2-3 times higher in patients with obesity and DM2 than in lean control subjects. This elevation is strongly related to increased blood glucose, decreased glucose tolerance, and decreased insulin sensitivity (42).

Vgontzas et al. (45) have shown that total sleep loss is associated with an increased secretion of IL-6. A more recent study from the same group (11), using a modest daily restriction of sleep by $2 \mathrm{~h} /$ night for 1 week in young healthy men and women, found that the mean concentration of IL-6 over a 24-h period was significantly increased (by $0.8 \pm 0.3 \mathrm{pg} / \mathrm{mL} ; \mathrm{P}<0.05)$ in both genders. On the other hand, Frey et al. (46), obtained different results when they studied 19 healthy men and women aged $28.05 \pm 8.56$ (mean \pm SD) in a condition of total sleep deprivation (40 h under constant routine conditions). Repeated-measures ANOVA with planned comparisons showed that acute total sleep deprivation induced a significant decrease in IL-6 levels (main effect of sleep deprivation $F(1,18)=4.774, P$ $<0.05$ ). Taken together, these findings suggest that one night of sleep loss triggers a stress response that includes stimulation of pro-inflammatory proteins in healthy young subjects (47). Because IL-6 is produced by many cells in the periphery, including endothelial cells, factors that affect the activation of these cells - for example, vasoconstriction and blood pressure -, are likely to be important determinants of the response to sleep loss (47). This suggests that mild sleep loss may also be associated with long-term risks of DM2.

\section{Leptin}

Leptin is an amino acid secreted by adipocytes in proportion to their total tissue mass. This hormone provides the appetite-regulating center in the brain with information about energy balance, and its release is associated with the promotion of satiety (48). Margetic et al. (49) suggested a peripheral interaction of leptin with insulin, mobilizing fuels and inhibiting energy storage mechanisms. Also, insulin has been shown to increase leptin production (48).

Although the principal biological effect of leptin in the central nervous system is the control of food intake and energy expenditure, in obesity there is a significant relationship between leptinemia and a chronic sub-inflammatory state. This relationship suggests other, possibly peripheral, biological effects associated with the cytokine-like structure of leptin (48). Indeed, an increased pro-inflammatory response has been observed in hyperleptinemia (50). Although the mechanisms accounting for this association have not been clearly identified, leptin is capable of increasing TNF- $\alpha$ production and macrophage activation (51).

On the other hand, accumulating evidence suggests that leptin promotes fatty acid oxidation and reduces fat accumulation in non-adipose tissues, thereby increasing insulin sensitivity. This effect is directly mediated by leptin by activation of the AMPK acting on certain skeletal muscles, and also indirectly through the hypothalamic-sympathetic nervous system axis (52). As a result of AMPK activation, the enzyme acetyl coenzyme A (CoA) carboxylase is inhibited, leading to reduced intracellular levels of the metabolite malonyl CoA. This alleviates the inhibition of fatty acid entry into the mitochondria and favors fatty acid oxidation (52), demonstrating the close relationship between leptin and lipid metabolism.

Both chronic partial sleep deprivation (53) and acute sleep deprivation (54) cause a reduction in the serum concentration of leptin. Spiegel et al. (54) evaluated the pattern of leptin secretion in 11 males subjected to a shortened sleep time ( $4 \mathrm{~h}$ ) for 6 nights. Mean and maximum leptin values were lower (by 19 and 26\%, respectively) during sleep restriction, compared to the same individuals when they had slept for a normal period of time $(8 \mathrm{~h})$. This result suggests that sleep plays an important role in promoting leptin secretion. In a cross-sectional study carried out with 1024 volunteers, Taheri et al. (55) also observed that short sleep was associated with low leptin levels, with a decrease of $15.5 \%$ occurring when subjects who habitually slept for 8 $\mathrm{h}$ were compared with those who habitually slept for $5 \mathrm{~h}$.

An effect of sleep duration on leptin levels could also reflect the impact of hormones that interact with leptin and are also modulated by sleep. Conversely, sleep-dependent alterations of leptin may result in alterations of leptinsensitive hormonal axes (54). Indeed, most prominent among the hormonal systems that interact with leptin as well as with sleep regulation are the HPA axis and glucose regulation by insulin.

\section{Adiponectin}

Adiponectin is a protein that is produced predominantly by adipocytes and has been shown to have anti-diabetic, anti-atherogenic, and anti-inflammatory properties (56). Like leptin, adiponectin enhances insulin sensitivity through activation of AMPK (57). Adiponectin also decreases hepatic glucose production by decreasing the mRNA expression of two essential enzymes involved in gluconeogenesis: phosphoenolpyruvate carboxykinase and glucose-6-phosphatase (56). Clinical and experimental observations 
indicate that low plasma levels of adiponectin contribute to the pathogenesis of insulin resistance and DM2 in obese or overweight patients (57).

Also, adiponectin can reduce the inflammatory response induced by TNF- $\alpha$, as shown by in vitro studies where macrophage activity and TNF- $\alpha$ production were diminished after treatment with adiponectin (56). Ablation of the adiponectin gene had no obvious metabolic effects in mice fed a chow diet; however, when they were fed a high fat/ sucrose diet, the knock-out mice developed severe insulin resistance accompanied by increased lipid deposition in muscle. Adipose tissue and plasma TNF- $\alpha$ levels were increased as a result of adiponectin deficiency, and these changes were reversed by adiponectin treatment (58). It appears that many of the anti-inflammatory properties of adiponectin arise from its anti-TNF- $\alpha$ effects.

Sleep loss leads to a decrease of adiponectin levels. Kotani et al. (59) measured fasting serum adiponectin levels in 109 healthy Japanese males who had regular lifestyles. Each subject's lifestyle was assessed by the self-administered Breslow Questionnaire (a well-established method to identify various lifestyles). Partial correlation analysis for serum adiponectin levels, after controlling for age and other lifestyle factors, revealed a significant negative correlation between serum adiponectin levels and body mass index (BMI; $r=$ $-0.222, P=0.025)$, and a significant positive correlation between serum adiponectin levels and sleep duration ( $r=$ $0.252, P=0.011$ ). No significant correlations were observed between adiponectin and other lifestyle factors. These data suggest that increased $\mathrm{BMI}$ and shorter sleep duration might, via the associated low serum adiponectin levels, act as risk factors for insulin resistance and DM2.

Further studies are required to understand how

\section{References}

1. Spiegel K, Knutson K, Leproult R, Tasali E, Van Cauter E. Sleep loss: a novel risk factor for insulin resistance and type 2 diabetes. J Appl Physiol 2005; 99: 2008-2019.

2. National Sleep Foundation. "Sleep in America" Poll. Washington: National Sleep Foundation; 2002.

3. Pires ML, Benedito-Silva AA, Mello MT, Del Giglio S, Pompeia C, Tufik S. Sleep habits and complaints of adults in the city of São Paulo, Brazil, in 1987 and 1995. Braz J Med Biol Res 2007; 40: 1505-1515.

4. Van Cauter E, Blackman JD, Roland D, Spire JP, Refetoff S, Polonsky KS. Modulation of glucose regulation and insulin secretion by circadian rhythmicity and sleep. $J$ Clin Invest 1991; 88: 934-942.

5. Spiegel K, Leproult R, Van Cauter E. Impact of sleep debt on metabolic and endocrine function. Lancet 1999; 354: 1435-1439.

6. Ayas NT, White DP, Manson JE, Stampfer MJ, Speizer FE, Malhotra A, et al. A prospective study of sleep duration and coronary heart disease in women. Arch Intern Med 2003; 163: 205-209. adipokines are involved in glucose metabolism and the mechanisms by which sleep seems to play an important role in their release. Such an understanding would add to knowledge about some of the factors that alter glucose metabolism.

\section{Conclusions}

There are many studies showing that sleep loss contributes to the onset of insulin resistance and DM2. The mechanisms involved in the impaired glucose metabolism seem to act via a decreased efficacy of the HPA axis and $\mathrm{GH}$ secretion. In addition, the modified release of adipokines - especially IL-6, TNF- $\alpha$ and adiponectin - during stress and following disturbances of the sleep pattern leads to a systemic chronic sub-inflammatory state in the adipose tissue that could play a central role in the development of insulin resistance and DM2. However, further studies are necessary to better elucidate the role of sleep loss in adipokine release and its relationship with glucose metabolism, which could be important to avoid the increased prevalence of DM2 in populations chronically exposed to sleep loss, such as shift workers. This is an exciting new field of study, and elucidation of the mechanisms involved might have profound implications for an understanding of these disorders and for public health.

\section{Acknowledgments}

Research supported by AFIP, Sleep Institute, FAPESP, CEDIP/FAPESP (\#998/14303-3), CEPE, UNIFESP, CENESP/UNIFESP, FADA, CEMSA, CAPES, CNPq, and FADA/UNIFESP.
7. Nilsson PM, Roost M, Engstrom G, Hedblad B, Berglund G. Incidence of diabetes in middle-aged men is related to sleep disturbances. Diabetes Care 2004; 27: 2464-2469.

8. Mallon L, Broman JE, Hetta J. High incidence of diabetes in men with sleep complaints or short sleep duration: a 12-year follow-up study of a middle-aged population. Diabetes Care 2005; 28: 2762-2767.

9. Trenell MI, Marshall NS, Rogers NL. Sleep and metabolic control: waking to a problem? Clin Exp Pharmacol Physiol 2007; 34: 1-9.

10. Kotani K, Shimohiro H, Sakane N. Mood change tendency and fasting plasma glucose levels in a Japanese female population. Tohoku J Exp Med 2007; 213: 369-372.

11. Vgontzas AN, Zoumakis E, Bixler EO, Lin HM, Follett $H$, Kales A, et al. Adverse effects of modest sleep restriction on sleepiness, performance, and inflammatory cytokines. $J$ Clin Endocrinol Metab 2004; 89: 2119-2126.

12. Gottlieb DJ, Punjabi NM, Newman AB, Resnick HE, Redline $\mathrm{S}$, Baldwin CM, et al. Association of sleep time with diabetes mellitus and impaired glucose tolerance. Arch Intern Med 
2005; 165: 863-867.

13. Chaput JP, Despres JP, Bouchard C, Astrup A, Tremblay A. Sleep duration as a risk factor for the development of type 2 diabetes or impaired glucose tolerance: analyses of the Quebec Family Study. Sleep Med 2009; 10: 919-924.

14. Yaggi HK, Araujo AB, McKinlay JB. Sleep duration as a risk factor for the development of type 2 diabetes. Diabetes Care 2006; 29: 657-661.

15. Cappuccio FP, D'Elia L, Strazzullo P, Miller MA. Quantity and quality of sleep and incidence of type 2 diabetes: a systematic review and meta-analysis. Diabetes Care 2010; 33: $414-420$.

16. Meisinger $\mathrm{C}$, Heier $M$, Lowel $H$, Schneider A, Doring $A$. Sleep duration and sleep complaints and risk of myocardial infarction in middle-aged men and women from the general population: the MONICA/KORAAugsburg cohort study. Sleep 2007; 30: 1121-1127.

17. Stranges S, Dorn JM, Cappuccio FP, Donahue RP, Rafalson LB, Hovey KM, et al. A population-based study of reduced sleep duration and hypertension: the strongest association may be in premenopausal women. $J$ Hypertens 2010; 28: 896-902.

18. Tuomilehto H, Peltonen M, Partinen M, Seppa J, Saaristo T, Korpi-Hyovalti E, et al. Sleep duration is associated with an increased risk for the prevalence of type 2 diabetes in middle-aged women - The FIN-D2D survey. Sleep Med 2008; 9: 221-227.

19. Barrett-Connor E, Khaw KT. Endogenous sex hormones and cardiovascular disease in men. A prospective populationbased study. Circulation 1988; 78: 539-545.

20. Haffner SM, Karhapaa P, Mykkanen L, Laakso M. Insulin resistance, body fat distribution, and sex hormones in men. Diabetes 1994; 43: 212-219.

21. Stellato RK, Feldman HA, Hamdy O, Horton ES, McKinlay JB. Testosterone, sex hormone-binding globulin, and the development of type 2 diabetes in middle-aged men: prospective results from the Massachusetts male aging study. Diabetes Care 2000; 23: 490-494.

22. Marin $P$. Testosterone and regional fat distribution. Obes Res 1995; 3 (Suppl 4): 609S-612S.

23. Pasquali R, Macor C, Vicennati V, Novo F, De lasio R, Mesini $P$, et al. Effects of acute hyperinsulinemia on testosterone serum concentrations in adult obese and normal-weight men. Metabolism 1997; 46: 526-529.

24. Luboshitzky R, Zabari Z, Shen-Orr Z, Herer P, Lavie P. Disruption of the nocturnal testosterone rhythm by sleep fragmentation in normal men. J Clin Endocrinol Metab 2001; 86: 1134-1139.

25. Wilcox G. Insulin and insulin resistance. Clin Biochem Rev 2005; 26: 19-39.

26. Bergman RN. Lilly lecture 1989. Toward physiological understanding of glucose tolerance. Minimal-model approach. Diabetes 1989; 38: 1512-1527.

27. Mander B, Colecchia E, Spiegel K, Kim R, Sannar E, Van Cauter E. Short sleep: a risk factor for insulin resistance and obesity. Diabetes 2001; 50 (Suppl 2): A45.

28. Spiegel K, Leproult R, Colecchia EF, L'Hermite-Baleriaux M, Nie Z, Copinschi G, et al. Adaptation of the 24-h growth hormone profile to a state of sleep debt. Am J Physiol Regul Integr Comp Physiol 2000; 279: R874-R883.

29. Plat L, Byrne MM, Sturis J, Polonsky KS, Mockel J, Fery F, et al. Effects of morning cortisol elevation on insulin secretion and glucose regulation in humans. Am J Physiol 1996; 270 : E36-E42.

30. Leproult R, Copinschi G, Buxton O, Van Cauter E. Sleep loss results in an elevation of cortisol levels the next evening. Sleep 1997; 20: 865-870.

31. Plat L, Leproult R, L'Hermite-Baleriaux M, Fery F, Mockel J, Polonsky KS, et al. Metabolic effects of short-term elevations of plasma cortisol are more pronounced in the evening than in the morning. J Clin Endocrinol Metab 1999; 84: 30823092.

32. Takahashi Y, Kipnis DM, Daughaday WH. Growth hormone secretion during sleep. J Clin Invest 1968; 47: 2079-2090.

33. Honda Y, Takahashi K, Takahashi S, Azumi K, Irie M, Sakuma M, et al. Growth hormone secretion during nocturnal sleep in normal subjects. J Clin Endocrinol Metab 1969; 29: 20-29.

34. Moller N, Jorgensen JO, Schmitz O, Moller J, Christiansen $\mathrm{J}$, Alberti KG, et al. Effects of a growth hormone pulse on total and forearm substrate fluxes in humans. Am J Physiol 1990; 258: E86-E91.

35. Fantuzzi G. Adipose tissue, adipokines, and inflammation. $J$ Allergy Clin Immunol 2005; 115: 911-919.

36. Ronti T, Lupattelli G, Mannarino E. The endocrine function of adipose tissue: an update. Clin Endocrinol 2006; 64: 355365.

37. Antuna-Puente B, Feve B, Fellahi S, Bastard JP. Adipokines: the missing link between insulin resistance and obesity. Diabetes Metab 2008; 34: 2-11.

38. Mullington JM, Haack M, Toth M, Serrador JM, Meier-Ewert HK. Cardiovascular, inflammatory, and metabolic consequences of sleep deprivation. Prog Cardiovasc Dis 2009; 51: 294-302.

39. Hotamisligil GS. Molecular mechanisms of insulin resistance and the role of the adipocyte. Int J Obes Relat Metab Disord 2000; 24 (Suppl 4): S23-S27.

40. Franklin CM. Clinical experience with soluble TNF p75 receptor in rheumatoid arthritis. Semin Arthritis Rheum 1999; 29: 172-181.

41. Krueger JM, Rector DM, Churchill L. Sleep and cytokines. Sleep Med Clin 2007; 2: 161-169.

42. Glund S, Deshmukh A, Long YC, Moller T, Koistinen HA, Caidahl K, et al. Interleukin-6 directly increases glucose metabolism in resting human skeletal muscle. Diabetes 2007; 56: $1630-1637$.

43. Al-Khalili L, Bouzakri K, Glund S, Lonnqvist F, Koistinen HA, Krook A. Signaling specificity of interleukin- 6 action on glucose and lipid metabolism in skeletal muscle. Mol Endocrinol 2006; 20: 3364-3375.

44. Carey AL, Steinberg GR, Macaulay SL, Thomas WG, Holmes AG, Ramm G, et al. Interleukin-6 increases insulinstimulated glucose disposal in humans and glucose uptake and fatty acid oxidation in vitro via AMP-activated protein kinase. Diabetes 2006; 55: 2688-2697.

45. Vgontzas AN, Papanicolaou DA, Bixler EO, Lotsikas A, Zachman K, Kales A, et al. Circadian interleukin-6 secretion and quantity and depth of sleep. J Clin Endocrinol Metab 1999; 84: 2603-2607.

46. Frey DJ, Fleshner M, Wright KP Jr. The effects of 40 hours of total sleep deprivation on inflammatory markers in healthy young adults. Brain Behav Immun 2007; 21: 1050-1057.

47. Boesen EI, Pollock DM. Effect of chronic IL-6 infusion on acute pressor responses to vasoconstrictors in mice. $\mathrm{Am} \mathrm{J}$ 
Physiol Heart Circ Physiol 2007; 293: H1745-H1749.

48. Ahima RS, Flier JS. Adipose tissue as an endocrine organ. Trends Endocrinol Metab 2000; 11: 327-332.

49. Margetic S, Gazzola C, Pegg GG, Hill RA. Leptin: a review of its peripheral actions and interactions. Int $J$ Obes Relat Metab Disord 2002; 26: 1407-1433.

50. Loffreda S, Yang SQ, Lin HZ, Karp CL, Brengman ML, Wang DJ, et al. Leptin regulates proinflammatory immune responses. FASEB J 1998; 12: 57-65.

51. Bjorbaek $C$, Kahn BB. Leptin signaling in the central nervous system and the periphery. Recent Prog Horm Res 2004; 59: 305-331.

52. Ruderman NB, Saha AK. Metabolic syndrome: adenosine monophosphate-activated protein kinase and malonyl coenzyme A. Obesity 2006; 14 (Suppl 1): 25S-33S.

53. Mullington JM, Chan JL, Van Dongen HP, Szuba MP, Samaras J, Price NJ, et al. Sleep loss reduces diurnal rhythm amplitude of leptin in healthy men. J Neuroendocrinol 2003; 15: 851-854.
54. Spiegel K, Leproult R, L'Hermite-Baleriaux M, Copinschi G, Penev PD, Van Cauter E. Leptin levels are dependent on sleep duration: relationships with sympathovagal balance, carbohydrate regulation, cortisol, and thyrotropin. J Clin Endocrinol Metab 2004; 89: 5762-5771.

55. Taheri S, Lin L, Austin D, Young T, Mignot E. Short sleep duration is associated with reduced leptin, elevated ghrelin, and increased body mass index. PLoS Med 2004; 1: e62.

56. Trujillo ME, Scherer PE. Adiponectin - journey from an adipocyte secretory protein to biomarker of the metabolic syndrome. J Intern Med 2005; 257: 167-175.

57. Guerre-Millo M. Adiponectin: an update. Diabetes Metab 2008; 34: 12-18.

58. Maeda N, Shimomura I, Kishida K, Nishizawa H, Matsuda M, Nagaretani $\mathrm{H}$, et al. Diet-induced insulin resistance in mice lacking adiponectin/ACRP30. Nat Med 2002; 8: 731-737.

59. Kotani K, Sakane N, Saiga K, Kato M, Ishida K, Kato Y, et al. Serum adiponectin levels and lifestyle factors in Japanese men. Heart Vessels 2007; 22: 291-296. 